\title{
Recombinant binder of sperm protein1 (rec-BSP1) as a potent fertility factor mediates its effect on spermatozoa and production of blastocysts in buffalo
}

Sudam Baga , Shama Ansari a , Alka Turuk ${ }^{\mathrm{b}}$, Nimai Charan Mahanandia ${ }^{\mathrm{a}}$, Sikander Saini $^{\mathrm{a}}$, Satya Kumar Biswal ${ }^{\mathrm{c}}$, Sandeep Kumar Singh ${ }^{\mathrm{d}}$, Praveen Malik ${ }^{\mathrm{d}}$, Satish Kumar ${ }^{\mathrm{a}}$ and Dhruba $\underline{\text { Malakar }^{a^{*}}}$

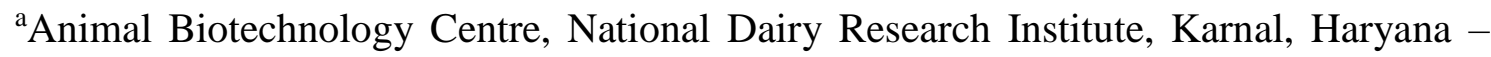
132001 India

${ }^{\mathrm{b}}$ Indian Council of Medical Research, New Delhi, India

${ }^{\mathrm{c} B i o i n f o r m a t i c s, ~ O U A T, ~ B h u b a n e s w a r-751003, ~ I n d i a ~}$

${ }^{\mathrm{d} C C S}$ National Institute of Animal Health, Baghpat-250609 UP, India

${ }^{\text {e}}$ Department of Animal Husbandry \& Dairying, Ministry of Fisheries \& AHD, Government of India.

*Corresponding author email- dhrubamalakar@gmail.com

Objective: To understand the effect of recombinant BSP1 (rec-BSP1) on in vitro capacitation of sperm and fertilization study

Method(s): Articles were screened for reports including rec-BSP1, Capacitation, in vitro fertilization

Intervention: None

Main Outcome Measure(s): Reproductive outcomes, effect on gametes and embryos

Result(s): Here we report an optimization of condition for rec-BSP1 production which was used for in vitro capacitation and enhancement of buffalo embryo production. The sequence of the protein was used for multiple sequence alignment which has 99\% similarity with PDC 109 protein. The expression of rec-BSP1 was carried out successfully with $1 \mathrm{mM}$ IPTG at $16^{\circ} \mathrm{C}$ for $22 \mathrm{hrs}$ and purified it in soluble form. The structure of rec-BSP1 was generated using 3D modelling and analysed its mode of binding with heparin and PC by molecular docking and the structural stability of rec-BSP1-PC and rec-BSP1-heparin complexes by using molecular dynamic (MD) simulation. The effect of rec-BSP1 was observed on in vitro capacitation of spermatozoa and buffalo blastocyst production. It was found that 
the rec-BSP1 enhanced the sperm motility at a concentration of $50 \mu \mathrm{g} / \mathrm{ml}$ for $1 \mathrm{~h}$ of incubation without having any detrimental effect on the sperm morphology and a significant increase in blastocyst production at concentration of $50 \mu \mathrm{g} / \mathrm{ml} \mathrm{rec-BSP}$. Hence this finding represents a new insight and advance the prospective approach to develop a potential fertility factor in reproduction.

Conclusion(s): The purified rec-BSP1 may enhance on male fertility and mediated its effect on in vitro blastocyst production in buffalo.

Key Words: BSP, heparin, PC, MD simulation, fertility factor

Binding of sperm proteins (BSPs) (1) one of the major proteins of seminal plasma in male that contributes around $70 \%$ of total seminal plasma proteins (2). The BSPs have a unique structure and are involved diverse functions such as maintenance of survivability, motility, fertility of spermatozoa (3-10), capacitation (11), fertilization (12) and protective action against stressful conditions (13). It is believed that it plays a significant role in selection of high-quality sperms for successful fertilization. In general, all isoforms of BSP protein are having two fibronectins type II (FN2) domains separated by polypeptide linker. Each FN2 domain of BSPs is conserved among the family (14) which binds to different ligands like heparin, PC, gelatine, HDL, glycosaminoglycan (15-18). The binding induces conformational changes in the BSPs, which in turn induce cholesterol efflux, sperm capacitation and trigger acrosome reaction (19). The association of different ligands with BSPs has widely been studied to investigate the effect of fertility in males (20). However, the ligandbinding mechanism for rec-BSP1 and the function of rec-BSP1-ligand complexes are poorly explored. The native purification of PDC-109 protein from buffalo was done by conventional method which is antigenically similar to BSP protein in buffalo (21, 22). The availability of pure BSPs can help in the studies related to improvement of fertilization and cryopreservation of spermatozoa of buffalo for faster multiplication of superior germplasm. The paucity of tissue sample is a main hurdle in the purification of BSPs in its native form. The recombinant expression of BSPs is an appropriate alternative to the native pure proteins provided the recombinant proteins are properly folded. There are no available reports on the use of buffalo rec-BSP1 in in vitro capacitation and embryo production. Therefore, the present study was 
envisaged to understand the mode of binding of buffalo rec-BSP1 on heparin and PC which play a significant role in capacitation of spermatozoa and effect on in vitro embryo production (23). The several computational approaches such as molecular modelling, docking, MD simulation, and binding free energy estimation were taken into consideration to understand the structural integrity of rec-BSP1 and mode of binding with these ligands. Keeping in view of lower rate of fertility in buffaloes, the present investigation has been conducted to develop a method for production of recombinant BSP in E. coli in soluble form and establishing its role in modulation of sperm morphology and function and evaluated its effect on in vitro buffalo embryo production.

\section{OBJECTIVE}

The aim of this review is currently known about the effect of rec-BSP1 on capacitation of sperm, in vitro production of embryos in buffalo

\section{METHODS}

\section{Retrieval Sequence of BSP1}

The nucleotide sequence of binder of sperm protein1 (BSP1) ( (Accession Number: KR703587.1) was retrieved from NCBI database. The nucleotide sequence was optimized and translated into protein sequence by using EMBOSS Transeq tool. This protein sequence was designated as recombinant binder of sperm protein (rec-BSP). For sequence analysis, the protein sequence of rec-BSP having similar sequence of other species such as human, mouse, pig, canine, horse and bovine were taken from UniProt database. Multiple sequence alignment between rec-BSP1 with selected sequences was performed by ClustalW2 program. Further, phylogenetic tree was constructed using Mega X software. In Mega X software, the sequences were aligned by muscle program using UPGMA method. The phylogeny tree was constructed by using maximum likelihood method (ML) based on JonesTaylor-Thornton (JTT) model with bootstrap value of 1000. Five numbers of discrete gamma distribution categories were taken into account for evolutionary rates using all sites. The tree was obtained by heuristic search using Nearest-Neighbor-Interchange 
(NNI) method; however, the initial tree was obtained by Neighbor Joining method in MEGA X program.

\section{Homology Modelling of rec-BSP1}

The homology model of rec-BSP1 was built with the Modeller version 9.23 program. For identify suitable template for computational modeling of rec-BSP1, BLASTp tool against PDB (Protein Data Bank) database was used for identifying a suitable template of rec-BSP1. Modeller 9.23 facilitated for development of 50 raw models of which the models with the lowest discrete optimized protein energy (DOPE) score was selected. Further, the three-dimensional (3-D) structure was refined by ModRefiner algorithm (Dong $\mathrm{Xu}$ and Yang Zhang, 2011). The final model was validated by PROCHECK and model quality assessment and energy profile characterization was done by ERRAT and ProSA. For correctness and accuracy of 3D modeled of rec-BSP1 protein, $100 \mathrm{~ns}$ molecular dynamics simulation was performed using AMBER99SB-ILDN force field in Gromacs version 5.0.7 software.

\section{Selection of ligands}

The two-dimensional (2-D) structures of heparin and phosphatidylcholine (PC) were retrieved from PubChem and ChEBI database. The 2-D structures were converted to a three-dimensional (3D) structures using OpenBabel program (O'Boyle NM, Banck M., 2011). The generated structures were then subjected to energy minimization by using the amber ff14sb force field in the UCSF Chimera tool. Further, these molecules were prepared for molecular docking with rec-BSP1.

\section{Molecular Docking}

The modeled structure of rec-BSP1 and two molecules (Heparin \& PC) were used as target and ligands respectively. The molecular docking was performed by using AutoDock 4.2.6 tool. The polar hydrogen and Kollman charges were applied to the structure of rec-BSP1. Geister partial charges were applied for both ligands. The 3D grid box with dimensions $\mathrm{X}=70 \mathrm{~A}^{0}, \mathrm{Y}=70 \mathrm{~A}^{0}$, and $\mathrm{Z}=70 \mathrm{~A}^{0}$ with grid-point center $\mathrm{X}$ $=40.044 \mathrm{~A}^{0}, Y=18.668 \mathrm{~A}^{0}, \mathrm{Z}=25.432 \mathrm{~A}^{0}$ and the grid spacing of $0.375 \mathrm{~A}^{0}$ were made to cover the binding cavity of rec-BSP1. The Lamarckian genetic algorithm (LGA) was employed to perform molecular docking in AutoDock. During the docking process, a maximum of 50 conformers were considered for each ligand which was set 
to terminate after 2500000 energy evaluations. The best docking conformation of the rec-BSP1 and ligands was visualized by Pymol.

\section{MD simulation of rec-BSP1 and selected ligands}

The best binding mode of rec-BSP1 and ligands complexes were subjected to molecular dynamics simulation by GROMACS version 5.0.7 package. MD simulations were performed using GROMOS96 53a6 force field method (Oostenbrink et al., 2004). The heparin and PC topologies files were generated using PRODRAG web server. The protein-ligands complexes were solvated with TIP3P water model and a cubic box setting was done with a distance of $10 \mathrm{~A}^{0}$ between the edge of the box and protein surface. Further neutralization of the protein-ligands complex by $\mathrm{Na}^{+} / \mathrm{Cl}^{-}$ ions with $0.15 \mathrm{M}$ ionic strength and energy minimization was done using steepest descent algorithm. After energy minimization, both complexes were subjected to equilibration using NVT (constant number of atoms, volume, and temperature) and NPT (constant number of atoms, pressure, and temperature) ensemble $300 \mathrm{~K}$ for $1 \mathrm{~ns}$. Finally, MD simulation of both complexes were run for $25 \mathrm{~ns}$ at a constant temperature (V-rescale method) and pressure (Parrinello-Rahman method) for trajectory analysis. Linear Constraint Solver (LINCS) algorithm was applied to constrain the covalent bonds and partial mesh Ewald method was used for calculating the electrostatic interactions. The cut-off radii for the coulomb and van der Waals interactions were fixed at $10.0 \mathrm{~A}^{0}$ and $14.0 \mathrm{~A}^{0}$. The MD trajectories snapshots saved at the interval of $100 \mathrm{ps}$ during the simulation period. To analyze the MD trajectories, GROMACS built-in modules utilities like root-mean-square deviation (RMSD), Radius of gyration (RG), Residue-based Root Mean Square Fluctuations (RMSF), Solvent accessible surface area (SASA) and inter-molecular hydrogen bond (H-Bond) were used. The 2D graphs were plotted using Xmgrace.

\section{Conformation of PCR products}

The optimized nucleotide sequence was amplified by one primer set designed in primer-blast software using Binder of sperm 1 (BSP1) mRNA ( complete CDS (KR703587) with standardized annealing temperature of $52^{\circ} \mathrm{C}$ and confirmed their size on $1 \%$ agarose gel. (F-5'AGCTGGATCCATGGCACTGCAGTT GGGGCTC 3'R-5'CTAGCTCGAGCTAATGGTGGTGGTGATGATGGCAATACT TCCAAGCTCTG TCCTT3'). 


\section{Sub-cloned in Expression vector and screening of recombinant plasmids}

In order to express BSP1, the expression vectors and recombinant plasmids were digested with $\mathrm{NdeI}$ and $\mathrm{XhoI}$ restriction enzymes. The purified inserts and vector were ligated in 3:1 molar ratio (24). The recombinant plasmids were transformed in E. Coli cell BL21 (DE3) for expression. Screening of the recombinant colonies was carried out by colony PCR and digested the plasmid DNA with NdeI and XhoI restriction enzymes for insert release (25).

\section{Purification and confirmation of rec-BSP1}

The expression conditions of the protein like IPTG concentration, temperature and incubation period were optimized for production of desired amount of rec-BSP1 in soluble form (26). The recombinant protein was expressed as 6x His tag fused to Nterminal of proteins hence it was purified by Ni-NTA agarose column. The protein was eluted from beads using $\mathrm{pH} 4.5$ buffers and purity of proteins checked on SDSPAGE (27). Further the protein was confirmed by Western Blot and quantified by Braford assay.

\section{In Vitro Capacitation study}

Semen samples were collected from Animal Breeding Research Center (ABRC), National Dairy Research Institute and $0.1 \mathrm{ml}$ of semen having concentration of 2-4 million spermatozoa/ml was transferred to $9 \mathrm{ml}$ of working Brackett and Oliphant (BO) (28) medium and centrifuged at $1200 \mathrm{rpm}$ for $7 \mathrm{~min}$. 2-3 washing was done using same BO medium. The resulting pellet was dissolved in BO medium and distributed in two groups (treatment \& control) which supplemented with concentration of $50 \mu \mathrm{g} / \mathrm{ml} \mathrm{rec-BSP1}$ and heparin at concentration of $20 \mu \mathrm{g} / \mathrm{ml}$ for incubation in a humidified $\mathrm{CO}_{2}$ incubator $\left(5 \% \mathrm{CO}_{2}, 95 \% \mathrm{RH}\right)$ at $38.5^{\circ} \mathrm{C}$ for $1-4 \mathrm{hr}$. The progressive motility of spermatozoa assessed by CASA and staining (Eosin, nigrosine \& trypan blue) was done for morphology of spermatozoa. Similarly, Hoechst staining was performed to assess the acrosome status of spermatozoa (29) and observed it under oil immersion lens (100X) using light microscope to evaluate the proportion of acrosome reactions. 


\section{In Vitro production of embryos in buffalo}

The effect of rec-BSP1 on in Vitro Fertilization study was done by treatment of different concentration $(20,50 \& 100 \mu \mathrm{g} / \mathrm{ml})$ of the recombinant protein and heparin at concentration of $20 \mu \mathrm{g} / \mathrm{ml}$ in fertilization BO medium. The processed spermatozoa and oocytes were co incubated for cleavage, blastocyst and hatched blastocysts formation. Ovaries were collected from slaughter house (Gazipur, Delhi) and processed for maturation in presence of exogenous hormonal supplement. COCs were cultured in group of $15-20$ nos in $100 \mu$ droplets of the IVM medium (TCM-199+10 $\% \mathrm{FBS}+5 \mu \mathrm{g} / \mathrm{ml} \mathrm{pFSH}+1 \mu \mathrm{g} / \mathrm{ml}$ estradiol- $17 \beta+0.81 \mathrm{mM}$ sodium pyruvate $+50 \mu \mathrm{g} / \mathrm{ml}$ gentamycin sulfate) and overlaid with sterile mineral oil in Petri dishes for $24 \mathrm{hr}$ in a humidified $\mathrm{CO}_{2}$ incubator $\left(5 \% \mathrm{CO}_{2}, 95 \% \mathrm{RH}\right)$ at $38.5^{\circ} \mathrm{C}$. The frozen semen was processed for capacitation of spermatozoa (2-4 million spermatozoa/ml) in fertilization BO medium supplemented with 20, 50, $100 \mu \mathrm{g} / \mathrm{ml} \mathrm{rec-BSP} 1$ and heparin incubated with matured oocytes for 16-18 hrs in a humidified $\mathrm{CO}_{2}$ incubator $(5 \%$ $\left.\mathrm{CO}_{2}, 95 \% \mathrm{RH}\right)$ at $38.5^{\circ} \mathrm{C}$ for in Vitro Fertilization. The presumptive zygotes were cultured on original beds of granulosa cells using media mCR2aa supplemented with different growth factors such as IGF-1, EGF, SCF to enhance the development of embryos into late blastocyst and hatching stage (30). Similarly, cysteamine, melatonin, ascorbic acid, mercapto ethanol and glutathione etc. were added to protect embryos from oxidative stress and cultured up to 8 days' post insemination in a humidified $\mathrm{CO}_{2}$ incubator $\left(5 \% \mathrm{CO}_{2}, 95 \% \mathrm{RH}\right)$ at $38.5^{\circ} \mathrm{C}$.

\section{RESULTS}

\section{Analysis of BSP Sequence}

The nucleotide sequence of mRNA of BSP (Bubalus bubalis) was retrieved from NCBI database. The nucleotide sequence was optimized by using Codon-Opt software and translated into protein sequences by EMBOSS Transeq tool. The similar BSP protein sequences of different species (human, mouse, pig, canine, horse and bovine) were taken from UniProt database for multiple sequence alignment by using ClustalW2 program (Supplementary fig. S1). The sequences were aligned by Muscle program using UPGMA method. MegaX software was used to reconstruct the phylogenetic tree by maximum likelihood (ML) method and LG model with 1000 
bootstrap replicates (Supplementary fig. S2). It was shown in the phylogenetic tree, the recombinant protein having $99 \%$ similarity with bovine seminal plasma protein PDC 109 (OS: Bos Taurus).

\section{Three Dimensional Modeling of rec-BSP1 and structure Validation}

Modeller v9.23 software was used to predict the three dimensional (3D) structure of rec-BSP1 sequence. Identification of template through BLASTp search reveals that, the structure of seminal plasma protein PDC-109 (Bos taurus) with PDB ID: 1H8P, Chain A with $81 \%$ query coverage, $86.73 \%$ sequence identity and structure of KDA type IV collagenase (Homo sapiens) with PDB ID: 1EAK, Chain A with $60 \%$ query coverage, $34.69 \%$ sequence identity were selected as templates for three dimensional (3D) modelling of the rec-BSP1 sequence. Modeller 9.23 employed to develop 50 raw models, the model with the lowest DOPE score and RMSD value was selected for further refinement. Galaxy Loop refinement protocol was applied to refined the loops. The refined model of rec-BSP1 was validated through various protein structure validation server. Ramachandran plot analysis for structural validation was confirmed that the model has 111 (93.3\%) amino acid residues in the favored regions, 6 (5\%) amino acid residues in additional allowed regions, 2 (1.7\%) in generously allowed regions and $0(0 \%)$ amino acid residue in the disallowed region. The Z-score (-3.91) for rec-BSP1 was calculated by Pro-SA web which is well within the range of experimental structure (Fig. 1 A, B). The validation of secondary structure of recBSP1 carried out by STRIDE web server (Fig. 1 C, D). For correctness and accuracy of 3D modeled of the rec-BSP1 protein, $100 \mathrm{~ns}$ MD simulation was performed using AMBER99SB-ILDN force field in Gromacs version 5.0.7 software (Fig.1 E, F, G). The rec-BSP1, the RMSD value was evaluated in order to check the stability of the complexes and it was shown that after a period of 100 ns indicating stable conformation of the modelled protein. 


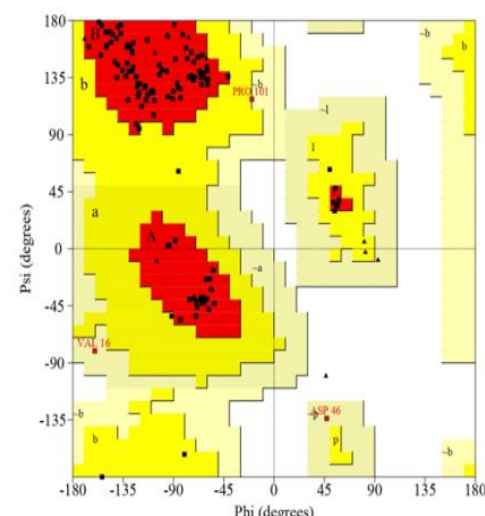

(A)

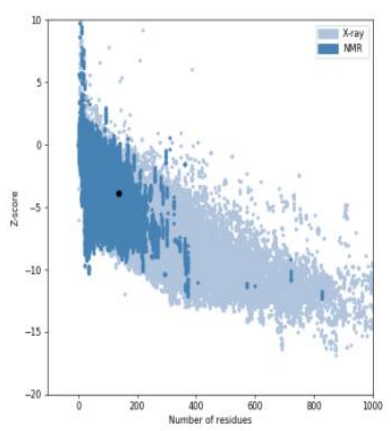

(B)

(C)

Bovine BSP1

1 MALQLGLFLIWAGVSVFLQLDPVNGNQDEGVFTELTQDRPAELPEDSVPDEERVFPFTYR 60

61 NRKHFDCTLRGS I FPWC SLDANYVGRWKYCAQRDYAKCVFPF I YGGKKYETCTKTGSMWM 120

121 SWCSLSPNYDKDRAWKYC

Legend of secondary structure icons:

\section{H Alpha-Helix}

- E Extanded Configuration (Beta-shet)

B Isolated Beta Bridge

b Isolated Beta Bridge (Type 3 Fig 4,cd) uㅔ I Pi-Helix
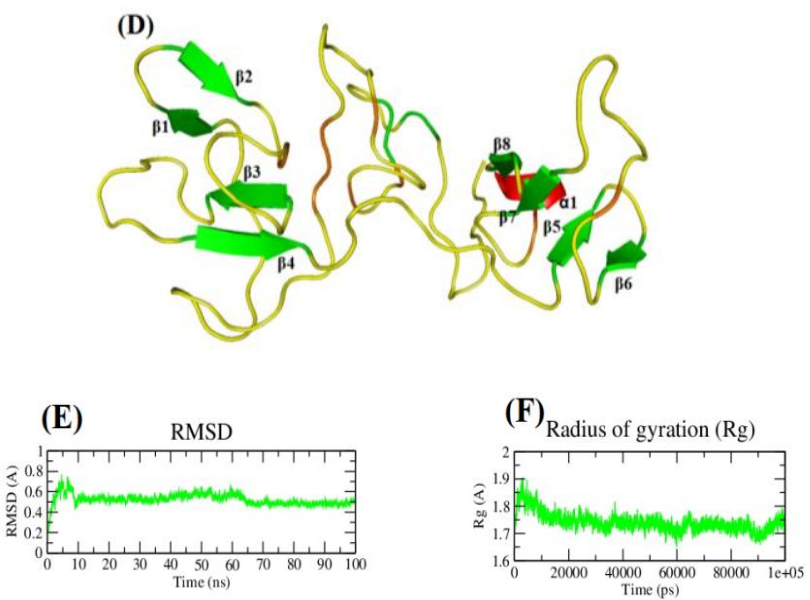

(G) RMS fluctuation (RMSF)

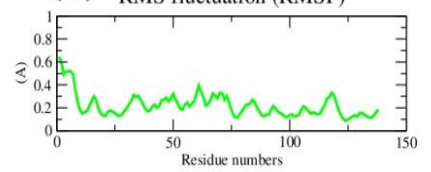

Figure1. 3D Structural model of rec-BSP1. (A) Overall quality of rec-BSP1 structure validation by using procheck for ramachandran plot. (B) rec-BSP1 structure validation using Pro-SA web server. (C) Secondary structure prediction of rec-BSP1. (D) 3D structure of rec-BSP1, the image was generated using PyMOL, where green 
color represent the Beta-Sheet and red color represent the Coil. (E) graphical representation of RMSD analysis of $100 \mathrm{~ns}$ simulation. (F) Radius gyration of $100 \mathrm{~ns}$ simulation. (G) RMSF analysis of 138 amino acid residues of rec-BSP1.

\section{Molecular Docking Analysis}

Two ligands were docked to rec-BSP1 using AutoDock 4.2.6 tool. The docking score was determined based on their binding energy, ligand efficiency (31) score and number of hydrogen bonds formed. Summary of the highest binding energy, ligand efficiency and number of hydrogen bonds formed of the ligands is presented (Supplementary Table. S3). The binding site of rec-BSP1 was predicted by metapocket 2.0 web-server (Bingding et al., 2009). The binding site of rec-BSP1 protein residues are ILE10, PHE17, LEU18, GLN19, LEU20, ASP21, VAL23, ASN24, GLY25, ASN26, GLN27, ASP28, GLU29, GLY30, VAL31, PHE32, THR33, GLU34, ASP38, ARG39, PRO40, GLU52, ARG53, VAL54, PHE55, PRO56, PHE65, and ASP66. These residues were selected during molecular docking preparation. The rec-BSP1-heparin complex has binding affinity $-7.4 \mathrm{kcal} / \mathrm{mol}$, with four conventional H-bonds whereas rec-BSP1-PC complex has binding affinity -7.4 $\mathrm{kcal} / \mathrm{mol}$, with four conventional H-bonds. The rec-BSP1-heparin and rec-BSP1-PC complexes were visualized through PyMol.
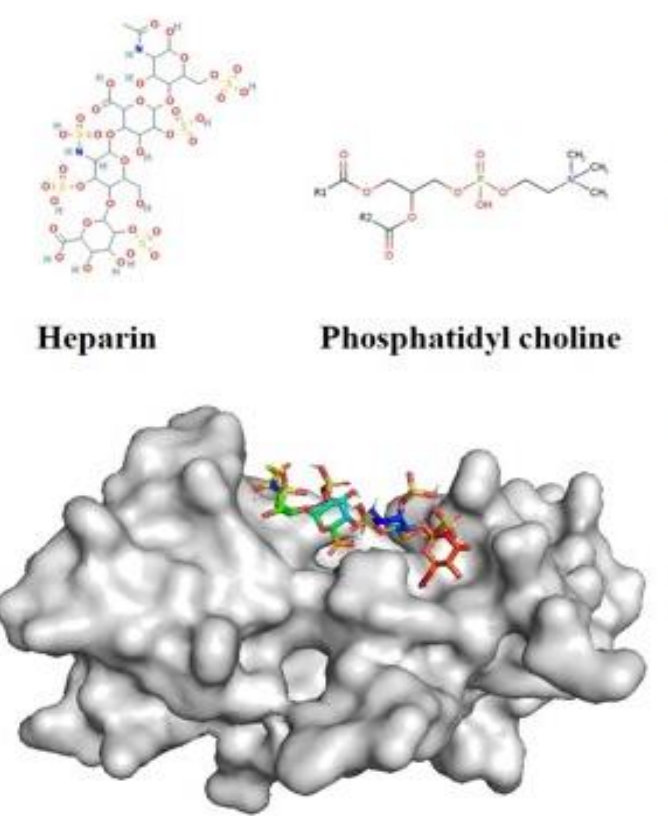

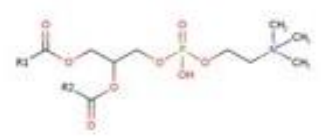

Phosphatidyl choline

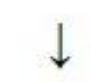




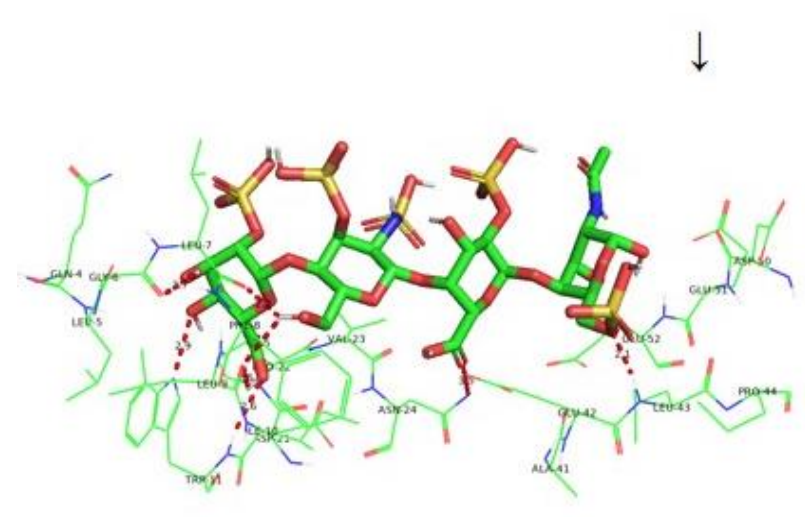

(A)

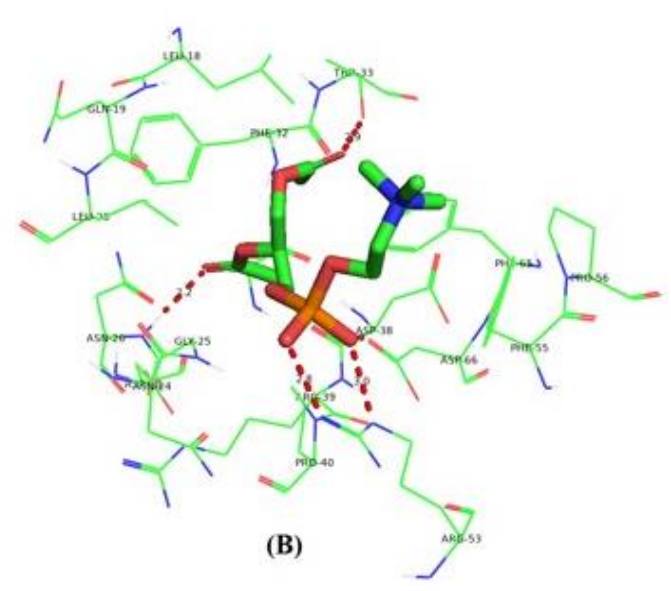

Figure 2. Docking pose of rec-BSP1-ligand complex. The structural representation the binding site of heparin and PC docked complex with interaction represented in red dotted lines. (A) Heparin docked complex. (B) PC docked complex.

\section{Simulation of Heparin and Phosphatidyl Choline docked Complexes}

The MD simulation was performed for the heparin and PC complex systems to understand the structural and dynamic stability of the rec-BSP1 when bind with the ligands. The intrinsic dynamical stability of the heparin and PC complex was studied by the root-mean-square deviation (RMSD), radius of gyration $\left(\mathrm{R}_{\mathrm{g}}\right)$, solvent accessible surface area (SASA) and root-mean-square fluctuation (RMSF) of the $\mathrm{C}_{\alpha}$ atom as a function of simulation time. RMSD measures the difference between the back bone of a protein from its initial structure to its final positions. The stability of protein-ligand complex relative to its preliminary state can be assessed by plotting the deviations produced over the course of simulation. The smaller deviation shows the more stability of the protein-ligand complexes. MD simulation was done to calculate the RMSD value in order to check stability of the complexes and it was shown that average deviation of heparin and PC complexes are approximately 0.43 and $0.89 \mathrm{~nm}$ during the course of $25 \mathrm{~ns}$ MD simulation. It is indicating that heparin is more stable than PC complex (fig. 3 A). Similarly, RMSF was carried out to understand flexibility and superimposed graphical representation of each residue. The RMSF value was calculated the magnitude of fluctuation of each residue and it was shown that the first complex with heparin having fluctuation range of approximately $0.4-0.7 \mathrm{~nm}$ in first 30 residues after that it showed average fluctuation of $0.4 \mathrm{~nm}$. Compared to heparin complex, the plot for PC Complex contain more noises and larger RMSF values, 
which indicates relatively a weak binding between the target and the substrates. The binding site residues predicted by Metapocket server which were all found to have less fluctuation for the rec-BSP1-heparin complex compared to rec-BSP1-PC complex indicating intactness and rigidity of the binding cavity (fig. 3 B). Radius of gyration value was calculated the compactness and structural changes of complex and observed that the average $\mathrm{Rg}$ value of $1.93 \mathrm{~nm}$ over the simulation period of $25 \mathrm{~ns}$ in the rec-BSP1-ligands complexes. The difference between the rec-BSP1-heparin complex relatively more stable than rec-BSP1-PC complex after a period of $7 \mathrm{~ns}$ (fig. $3 \mathrm{C}$ ). Analysis of SASA was done for the rec-BSP1 with heparin and PC complexes to understand their interaction and solvent accessibility. The average sasa value for heparin complex was 112, whereas PC complex $107 \mathrm{~nm}^{2}$ over a period of 25 ns MD simulation. It was shown that rec-BSP1-heparin complex has less fluctuation than rec-BSP1-PC complex (fig. 3 D). The analysis of hydrogen bond (34) between rec-BSP1 and the ligands were calculated for overall stability of protein-ligand complexes using gmx h-bond over 25 ns simulation period. The rec-BSP1-heparin complex having higher numbers of H-bond ( 2.229) compared to rec-BSP1-PC complex ( 0.638) (fig. 4 A). It indicates that rec-BSP1-heparin complex was more stable interacting complex. The MD trajectories result files were used for Principal component analysis (PCA) for determination of conformational changes w.r.t recBSP1 function. The eigenvalues were calculated the movement of atoms meant for conformational changes which were obtained by diagonalzing the covariance matrix of the $\mathrm{C} \alpha$ atomic fluctuations against the equivalent Eigenvectors indices. It was shown that the projection of trajectory along PC1 and PC2 and rec-BSP1-heparin has a higher value of trace of covariance matrix than PC indicating higher flexibility and increased collective motion. The rec-BSP1-heparin complex showed the least conformational changes due to decrease in collective motions than PC system. The PCA and RMSF investigations evoke similar change about structural fluctuations of the rec-BSP1-ligands complexes (fig. 4 B, C). DSSP algorithm was applied to check the secondary structure protein. It was observed that there was significant structural changes i.e. increase in helical content and absence of $\beta$-sheet in rec-BSP1 (fig. $4 \mathrm{D}$, E). 
(A)

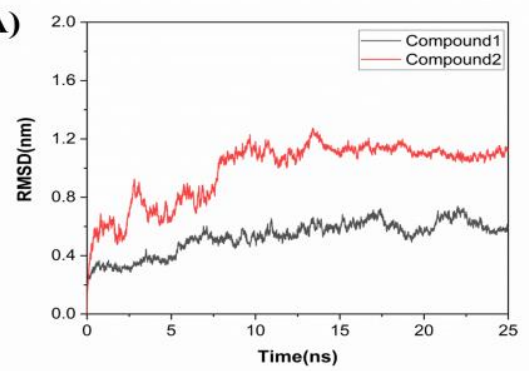

(C)

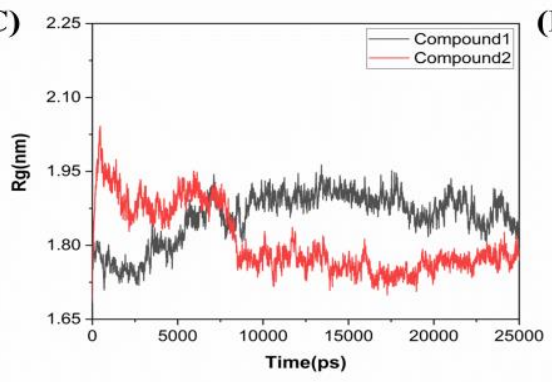

(B)

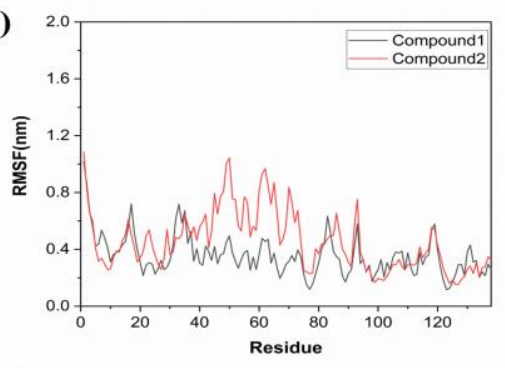

(D)

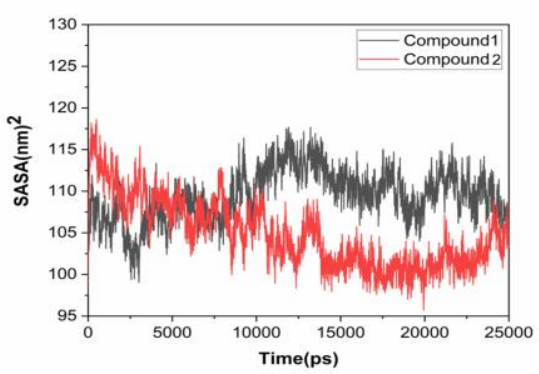

Figure 3. Dynamics stability of rec-BSP1 with heparin and PC complexes during 25 ns MD simulation. (A) RMSD analysis of ligand Compound1 (heparin, black), and Compound2 (PC, red) protein backbone conformation. (B) RMSF analysis of 138 amino-acid residues is represented for Compound (heparin, black) and Compound2 (PC, red) protein complexes. (C) Radius gyration of Compound1 (heparin, black) and Compound2 (PC, red). (D) Solvent accessible surface area (SASA) of Compound1 (heparin, black) and Compound2 (PC, red).

(A)

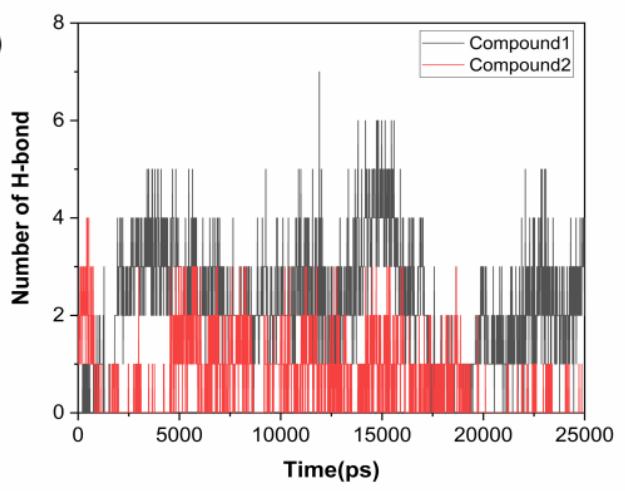


(B)

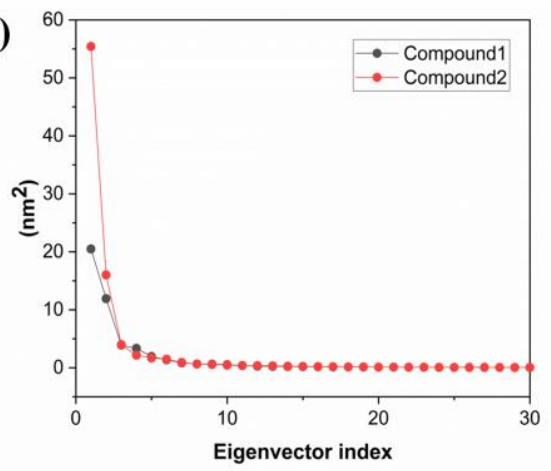

(D)

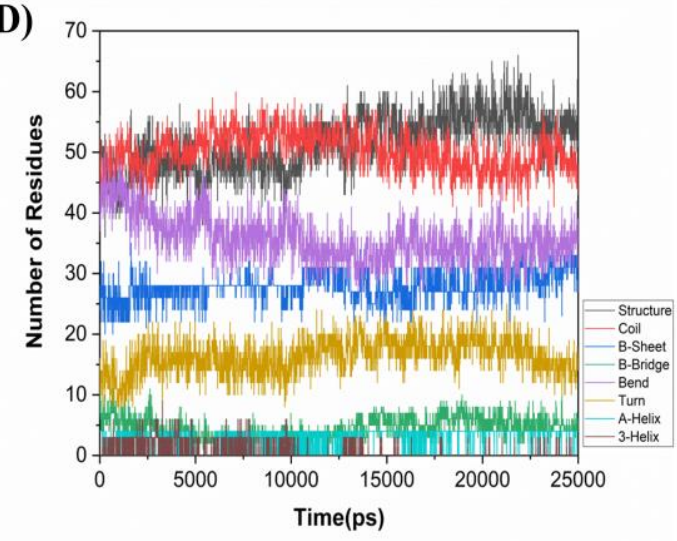

(C)

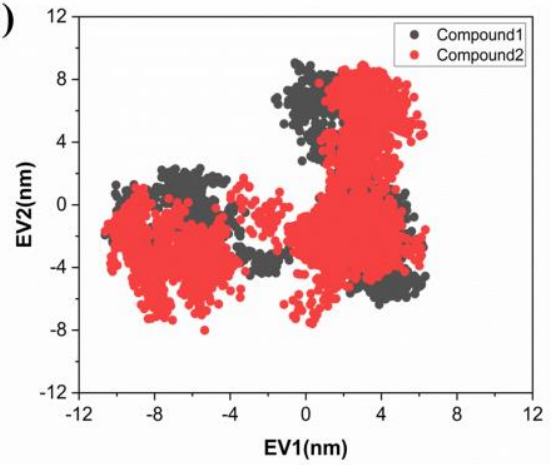

(E)

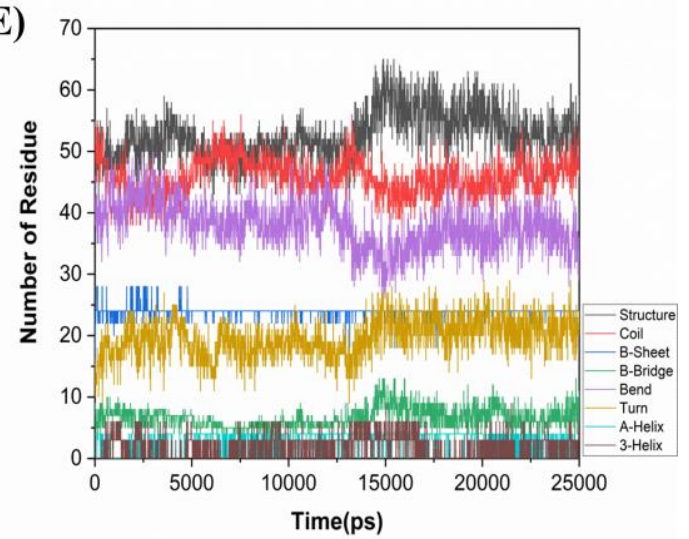

Figure4. Hydrogen bond formation by rec-BSP1 with Compound 1(heparin, black) and Compound2 (PC, red) during 25 ns simulation. (A)Principal component analysis of rec-BSP1 with heparin and PC complexes. (B) The plot displaying the eigenvalue of both Compound 1 (heparin, black) and Compound2 (PC, red) of the first 30 eigenvectors. (C)The 2D Projection motion of the Compound 1 (heparin, black) and Compound2 (PC, red) in phase space along the first two principal eigenvectors. Secondary structure changes during the course of $25 \mathrm{~ns}$ MD simulation in (D) Heparin; (E) PC.

\section{Binding Free Energy Calculation}

The binding free energy of rec-BSP1-ligand complexes were calculated using g_mmpbsa tool by molecular mechanics-based Poisson-Boltzmann Surface Area (35). In this study, 250 snapshots were taken from $25 \mathrm{~ns}$ MD trajectories and estimated the binding free energy for both complexes. The binding energy of rec-BSP1-heparin and rec-BSP1-PC complexes is $-126.937 \pm 95.414 \mathrm{KJ} / \mathrm{mol},-45.485$ $\pm 29.332 \mathrm{KJ} / \mathrm{mol}$. The vdW energy was calculated with higher negative value of rec-BSP1-heparin complex because of solvent accessible surface area energy 
( $\Delta$ Gsasa) and highest free energy due to Vander Waal, electrostatic interaction signifying the considerable hydrophobic interaction and stability of the rec-BSP1heparin complex compared to rec-BSP1-PC complex (Table.1).

Table 1. Binding free energies of Heparin and PC complexes.

\begin{tabular}{|l|l|l|}
\hline Energy components $(\mathbf{k J} / \mathbf{m o l})$ & Heparin & PC \\
\hline Van Der Waal energy $\left(\Delta \mathrm{G}_{\mathrm{vdW}}\right)$ & $-151.065 \pm 103.024$ & $-82.019 \pm 22.942$ \\
\hline Electrostatic energy $\left(\Delta \mathrm{G}_{\mathrm{ele}}\right)$ & $-51.488 \pm 44.724$ & $-8.879 \pm 16.056$ \\
\hline Polar solvation energy $\left(\Delta \mathrm{G}_{\mathrm{ps}}\right)$ & $90.919 \pm 67.678$ & $55.579 \pm 50.188$ \\
\hline SASA energy $\left(\Delta \mathrm{G}_{\mathrm{sasa}}\right)$ & $-15.305 \pm 10.014$ & $-10.166 \pm 2.529$ \\
\hline Binding energy $\left(\Delta \mathrm{G}_{\text {binding }}\right)$ & $-126.937 \pm 95.414$ & $-45.485 \pm 29.332$ \\
\hline
\end{tabular}

\section{Protein expression and purification}

The optimized sequence was amplified by designed primers set with standardized annealing temperature of $52^{\circ} \mathrm{C}$ and size of $468 \mathrm{bp}$ was observed on $1 \%$ agarose gel (Fig. 5A). The gene was cloned into pET28a vector containing sequences for T7 promotor/lac operator, a His-tag and NdeI/XhoI restriction sites. Further it was confirmed by RE digestion (Fig. 5 B), colonies PCR (Supplementary fig. S4) and sequencing (Fig. 5 C). The recombinant plasmids were transformed into E. coli BL21 (DE3) strain and induce for expression of rec-BSP1 with $1 \mathrm{mM}$ IPTG at $16^{\circ} \mathrm{C}$ for 22 h. The expressed His-tagged BSP1 was purified by Nickel Ion affinity chromatography and confirmed on SDS PAGE as a protein band of $\sim 17 \mathrm{kDa}$ (Fig. 6 A, B, C). The specificity checks and quantification were done by Western blot and Bradford assay (Fig. 6 D, E). 


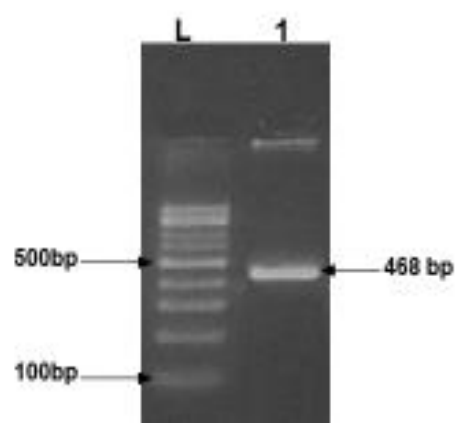

(A)

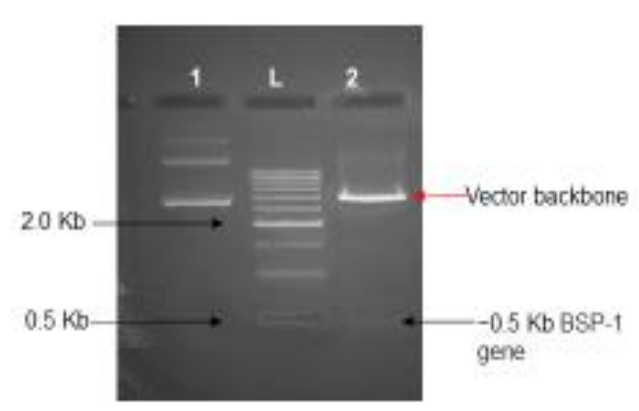

(B)

\begin{abstract}
5'CATATGGCCTTGCAGTTGGGTCTTTTCTTGATTTGGGCCGGAGTAAGCGTG TTTTTGCAGTTAGACCCTGTAAACGGGAACCAGGATGAAGGGGTCTTTACAG AACTGACCCAGGATCGCCCAGCCGAGCTGCCGGAGGACAGCGTACCAGATG AAGAAAGAGTATTCCCTTTCACGTATCGCAACCGTAAACATTTTGACTGTACA CTTAGAGGTAGCATCTTCCCCTGGTGTAGTCTGGATGCCAACTACGTGGGACG CTGGAAATACTGCGCGCAGCGTGACTACGCCAAGTGTGTCTTCCCTTTCATTT ACGGGGGTAAGAAATACGAGACCTGCACGAAGACGGGTTCAATGTGGATGTC CTGGTGCTCCTTATCGCCCAACTACGACAAAGATAGAGCCTGGAAGTATTGT CTCGAG CACCACCACCACCACCAC TGA 3'
\end{abstract}

Figure5. (A) PCR amplicon (lane1) loaded on 2\% agarose gel, L: DNA ladder agarose gel. (B) Restriction enzyme NdeI/ XhoI loaded on $1.5 \%$ (C) Sequence of expression construct (rec-buBSP1) intact ORF with His Tag-Black Highlight-RE sites (NdeI/XhoI), Blue Highlight-rec-BSP1 gene, Red Highlight-His tag \& stop codon.

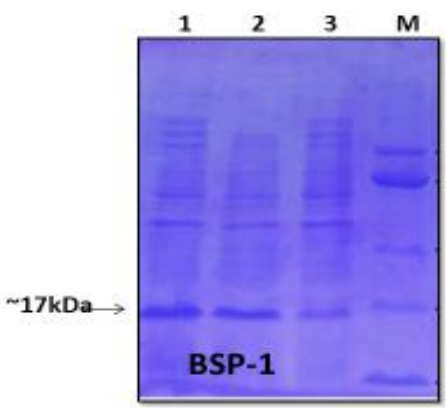

A

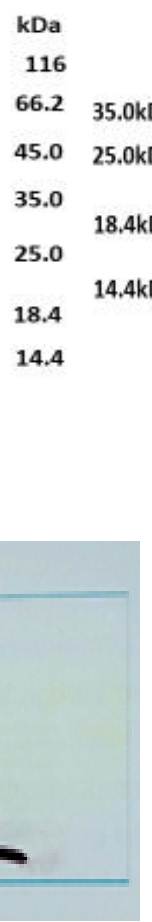

$\mathrm{D}$

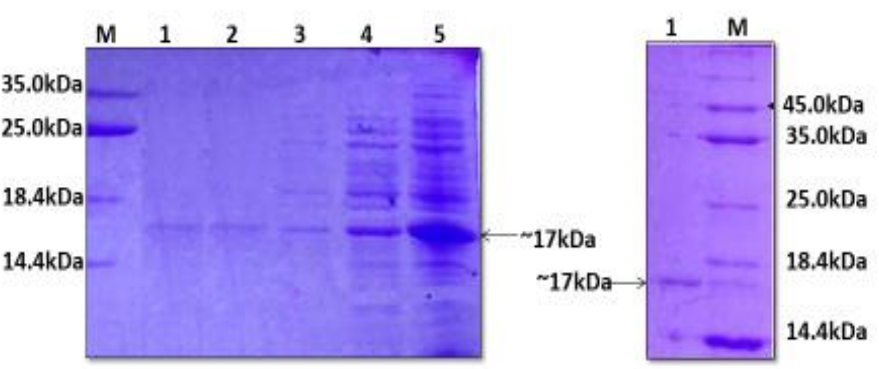

B

$\mathrm{C}$

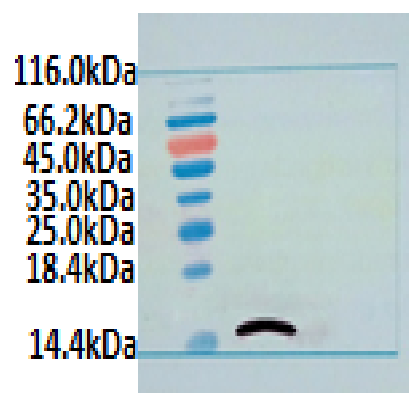

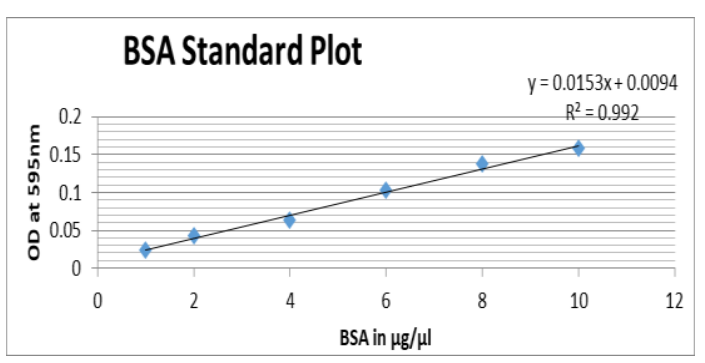

E 
Figure6. (A) Induction of PCR Positive Clones with $1 \mathrm{mM}$ IPTG at $16^{\circ} \mathrm{C}$. Lane 1: 16 hours after induction sample (whole cell extract), Lane2: 4 hours after induction sample (whole cell extract), Lane3: Before induction sample (whole cell extract) showing slight leaky expression, Lane M: Protein Marker (B) Pellet and Supernatants after sonication were loaded on 15\% SDS-PAGE where Lane 1: 1st sonication pellet, Lane 2: 2nd sonication pellet, Lane 3: 3rd sonication pellet, Lane 4: 4th sonication pellet, Lane 5: 4th sonication supernatant M: Marker $(\mathrm{C})$ dialyzed pooled elutes loaded on 15\% SDS-PAGE where Lane 1: Dialyzed pooled elutes; M: Marker. (D) Western Blot analysis of rec-BSP1 using anti his mouse Ab, HRP conjugate $2^{0} \mathrm{Ab}$ showed $\sim 17 \mathrm{kDa}$ size protein for confirmation (E) Standard curve for estimation of rec-BSP1 concentration.

\section{Checking of motility percentage and acrosome reaction status of spermatozoa}

The motility and acrosome reaction of spermatozoa were evaluated by computer assisted sperm analyzer (CASA), staining. It was observed a significant $(\mathrm{P}<0.05)$ increase in percentage of motility and AR in sperm treated with $50 \mu \mathrm{g} / \mathrm{ml}$ of rec-BSP1 at $1 \& 2 \mathrm{hr}$ and $2 \& 4 \mathrm{hr}$ of incubation as compared to heparin/control (Fig. $7 \mathrm{~A}, \mathrm{~B}$ ). The morphology of spermatozoa was found completely normal without any undesirable effect (Fig. 7 C, D).
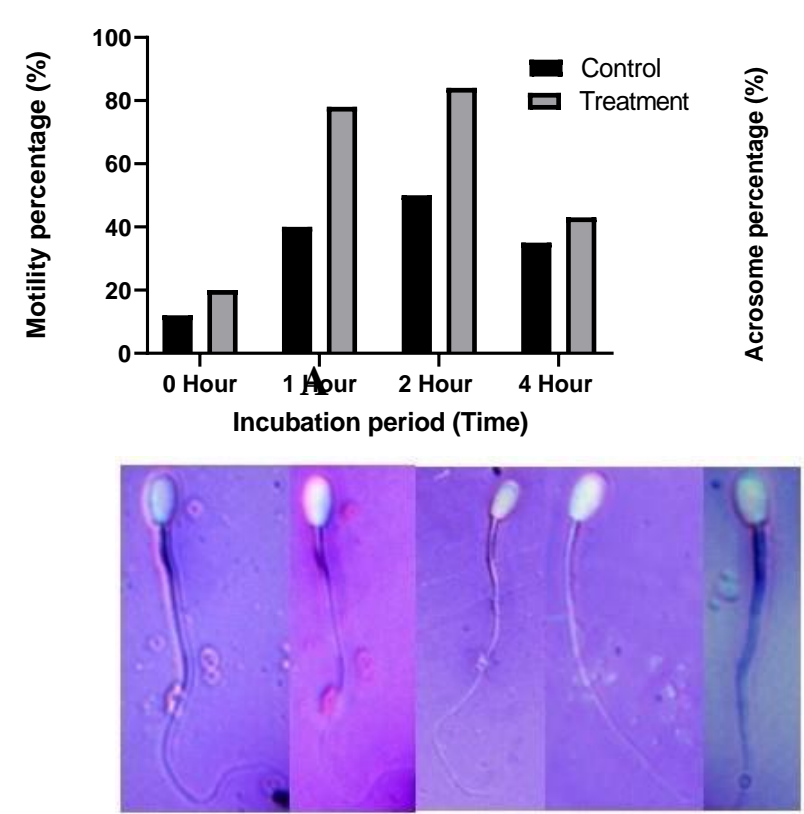

C
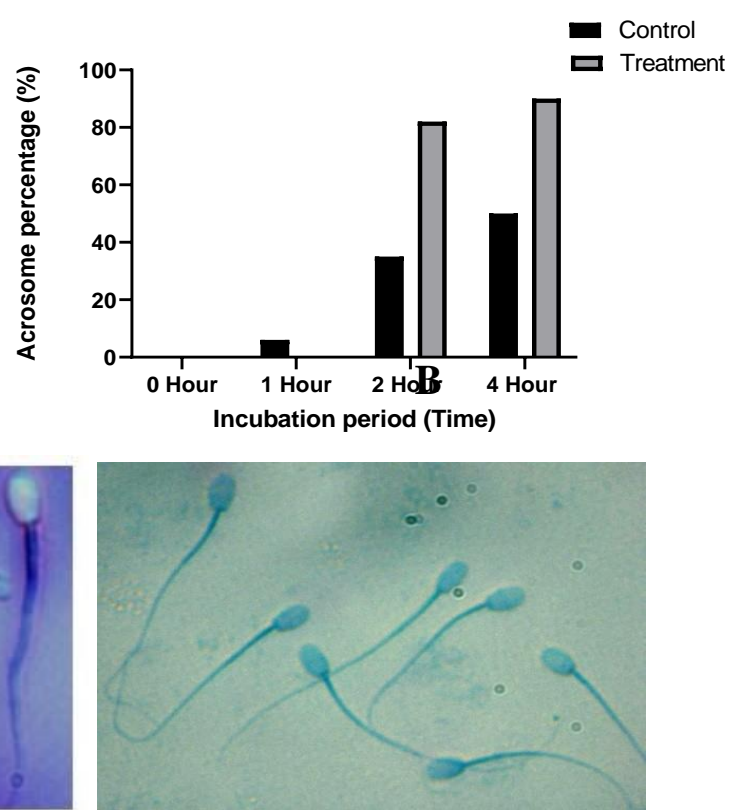

D 
Figure7. (A) Effect of $50 \mu \mathrm{g} / \mathrm{ml}$ rec-BSP1 and heparin in different incubation period (hours) on motility percentage of buffalos spermatozoa. (B) Effect of $50 \mu \mathrm{g} / \mathrm{ml} \mathrm{rec-}$ BSP1 and heparin in different incubation period (hours) on acrosome percentage of buffalos spermatozoa. (C) Eosin Nigrosin staining of buffalo spermatozoa; all live sperm head clearly was clearly visible and showing bright head in $50 \mu \mathrm{g}$ rec-BSP1 treatment group. (D) Trypan blue staining of buffalo spermatozoa; all sperm head was clearly visible and showing bright head in $50 \mu \mathrm{g}$ rec-BSP1 treatment group.

\section{Effect of rec-BSP1 on in vitro embryo production}

The effect of rec-BSP1 on in vitro buffalo embryo production was carried out with treatment of 20,50 and $100 \mu \mathrm{g} / \mathrm{ml}$ of rec-BSP1 and heparin at concentration of 20 $\mu \mathrm{g} / \mathrm{ml}$ and different stages of embryos (Fig.8). It was observed that the cleavage, blastocyst and hatched blastocyst production rate were significantly higher percentage in $50 \mu \mathrm{g} / \mathrm{ml}$ compare to 20 and $100 \mu \mathrm{g} / \mathrm{ml}$ of rec-BSP1 and control (heparin) (36) (Table.2). Further, hatched blastocysts were taken from $50 \mu \mathrm{g} / \mathrm{ml} \mathrm{rec-BSP1}$ treated group and control group for total cells counting by Hoechst 33342 staining. It was observed that there was significant increase of total cells number in hatched blastocysts in $50 \mu \mathrm{g} / \mathrm{ml}$ rec-BSP1 treated group compared to control (Fig. 9).

Table 2. Effect of rec-BSP1 on in Vitro Embryo production

\begin{tabular}{|l|c|c|c|c|}
\hline $\begin{array}{l}\text { Concentration } \\
\text { rec-BSP1 } \mu \mathrm{g} / \mathrm{ml}\end{array}$ & $\begin{array}{l}\text { No. of } \\
\text { oocytes }\end{array}$ & $\begin{array}{l}\text { Cleavage rate } \\
(\%)\end{array}$ & $\begin{array}{l}\text { Blastocyst rate } \\
(\%)\end{array}$ & $\begin{array}{l}\text { Hatched Blastocyst } \\
(\%)\end{array}$ \\
\hline Control (Heparin) & 303 & $177(58.41)$ & $34(19.21)$ & $31(16.95)$ \\
\hline 20 & 294 & $160(54.42)$ & $24(15.0)$ & $20(12.50)$ \\
\hline 50 & 305 & $198(64.91)$ & $51(25.75)$ & $44(22.22)$ \\
\hline 100 & 300 & $140(46.66)$ & $16(11.43)$ & $13(9.28)$ \\
\hline
\end{tabular}


bioRxiv preprint doi: https://doi.org/10.1101/2021.04.12.437362; this version posted April 13, 2021. The copyright holder for this preprint (which was not certified by peer review) is the author/funder, who has granted bioRxiv a license to display the preprint in perpetuity. It is made available under aCC-BY-ND 4.0 International license.
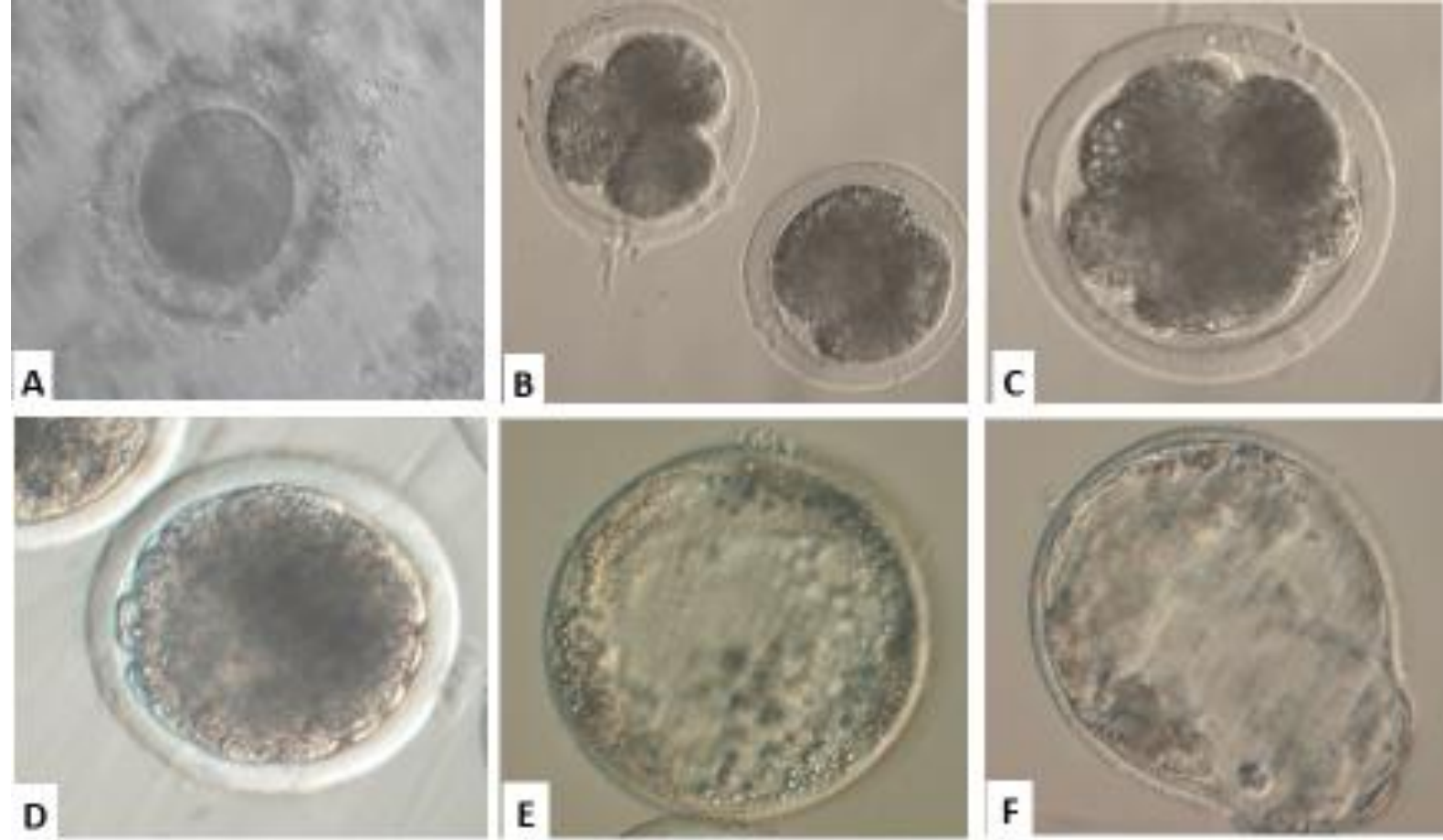

Fig: 8 (A) Sperm-Oocyte co-incubation, (B) 2-Cell \& 4-Cell, (C) 8-cell, (D) Morula, (E) Early Blastocyst, (F) Hatching blastocyst
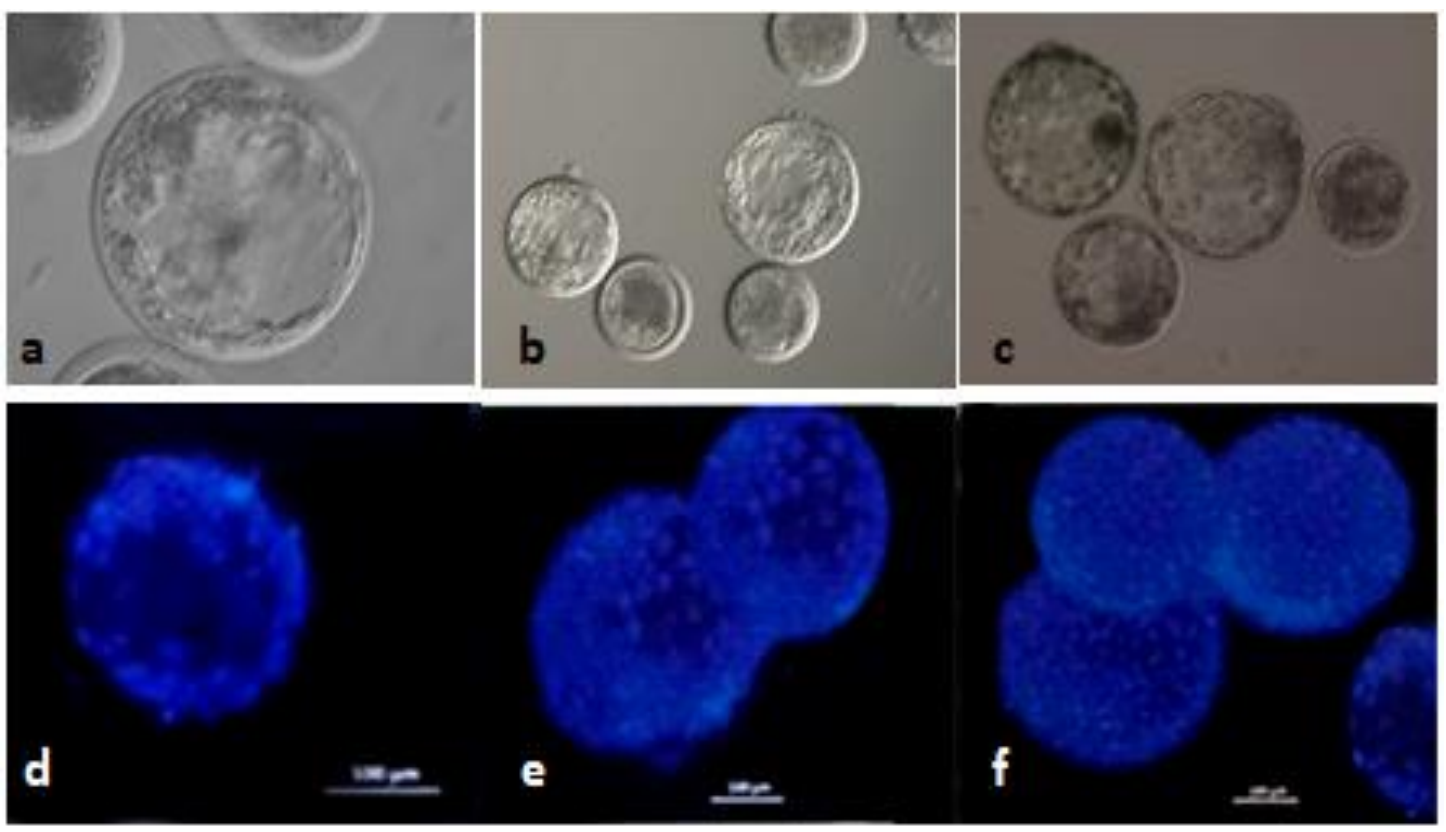

Figure 9. A few representative images of blastocyst and Hoechst staining of hatched blastocyst. Hatched /expanded /early blastocyst in control (a). Hatched blastocyst in IVF medium supplemented with $20 \mu \mathrm{g} / \mathrm{ml}$ of rBSP1 (b). Hatched blastocyst in IVF medium supplemented with $50 \mu \mathrm{g} / \mathrm{ml}$ of $\mathrm{rBSP} 1$ (c). Hoechst staining of blastocyst in control (d). Hoechst staining of blastocyst IVF (BO) medium supplemented with 20 
$\mu \mathrm{g} / \mathrm{ml}$ of rec-BSP1 (e). Hoechst staining of blastocyst IVF (BO) medium supplemented with $50 \mu \mathrm{g} / \mathrm{ml}$ of rec-BSP1 (f).

\section{DISCUSSION}

The mRNA sequence of BSP ( $\underline{\text { Bubalus }} \underline{\text { bubalis })}$ was taken from the NCBI database. The sequences were aligned by the Muscle program using the UPGMA method and MegaX software was used to reconstruct the phylogenetic tree by the maximum likelihood method. It was observed in the phylogenetic tree that the recombinant protein having 99\% similarity with bovine seminal plasma protein PDC 109 (OS: Bos Taurus). Three Dimensional Modeling of rec-BSPI was performed and further structure Validated of rec-BSP1 protein sequence and observed 138 amino acids. The active binding site of rec-BSPl was not known and probable binding sites of rec$B S P 1$ were predicted by the software Metapocket. Molecular docking analysis of recBSP1 was done using two ligands of heparin and phosphatidylcholine using AutoDock 4.2.6 tool. Molecular Docking simulation study was also carried out using GROMACS v 5.0.7 package under Amber99B-ILDN force field for understanding the dynamics and structural behavior of the $r B S P 1$ with the two ligands of heparin and phosphatidylcholine. The hydrogen bond was analyzed between $r B S P 1$ and the ligands and calculated for the overall stability of protein-ligand complexes using gmx bond over $25 \mathrm{~ns}$ simulation period. The sequence was optimized and designed the primers with a standardized annealing temperature of $52^{\circ} \mathrm{C}$ and a size of $468 \mathrm{bp}$ was observed and cloned the gene into cloning vectors. Then the cloned gene was further cloned into a pET28a expression vector containing sequences for T7 promoter/lac operator, a His-tag, and NdeI/XhoI restriction sites.

The rec-BSP1 expressed at $16^{\circ} \mathrm{C}$ was purified by Ni NTA affinity chromatography because 6 His tag fused with $\mathrm{N}$ terminal protein. The recombinant protein was bound and eluted from Ni NTA agarose bead using PH 4.5 buffer. The purified protein was visualized on SDS PAGE and further confirmed by Western blot analysis in which the membrane was incubated with anti-6x-His epitope tag mice (Thermofisher) at 1:1000 dilution. The secondary antibody HRPO conjugated Anti-Mouse IgG at 1:1000 dilutions and immunosignal was detected by 3, 3'-Diaminobenzidine (DAB) staining. We tried to examine its functional activities such as motility and 
morphology of spermatozoa by CASA study and staining (Eosin, nigrosine/trypan blue). The experiment revealed a significant increase in percentage motility and a significant number of spermatozoa with better morphology in the $50 \mu \mathrm{g} / \mathrm{ml} \mathrm{rec-BSP1}$ treated group as compared to the control. We developed a method for the expression of a soluble form of rec-BSP1 in the prokaryotic system and purified the rec-BSP1 which was confirmed by western blot. The rec-BSP1 was found to be effective for enhancing sperm motility and improving the morphology of spermatozoa and a significant increase in blastocyst production. Molecular docking and MD simulation experiments proofed that rec-BSP1 interacts with heparin with stronger affinity than PC and rec-BSP1 heparin complex is more stable than rec-BSP1 phosphatidylcholine complex. ProSA confirmed the consistency and robustness of the proposed homology model and heparin with the highest docking score seems to enhance the activity of the rec-BSP1 and crystal structure of seminal plasma protein PDC-109 as the best PDB template and need to be further analyzed.

\section{CONCLUSIONS}

In conclusion, this study of the role of rec-BSP1 in reproductive function may recognize a new fertility factor that can be beneficial to enhance male fertility. Applicably, the research work suggests that the proposed homology model of heparin may a suitable, consistent, and robust model with the highest docking score seems to improve the activity of rec-BSP1 and ultimately use as a potent fertility factor which enhances in vitro embryo production.

\section{Acknowledgments:}

This work is part of $\mathrm{PhD}$ thesis of $\mathrm{S}$. Bag, in Animal Biotechnology of ICAR-NDRI, Karnal (Deemed University), Haryana, India. The authors also acknowledge the Director, CCS National Institute of Animal Health, Baghpat, UP, Department of Animal Husbandry and Dairying, Government of India for providing necessary facilities for completion of the research work. 


\section{Authors' contributions}

SB (Sudam Bag) performed most of the experiments, analysis data and manuscript preparation. SA, SS, production of buffalo blastocysts, AT, NCM, SB, SS, SKS, assist in experiments of cloning, expression, purification, and embryo production research work and data analysis, and PM, SK, DM have been involved in final data analysis, manuscript preparation, and presentation.

\section{Competing interests}

All the authors declare that they have no conflict of interest.

\section{Ethical approval and informed consent}

Ethical approval was taken from Institute ethics committee, ICAR-National Dairy Research Institute (NDRI), Karnal, India during the study. All experiments were conducted as per the rules, guidelines, and regulations of ICAR-National Dairy Research Institute (NDRI), Karnal, India Institute Animal Ethics Committee. This research work was approved by the Institute of Animal Ethics Committee, NDRI, India and all methods were performed in accordance with the relevant guidelines and regulations though no animal participant involved in this research.

\section{REFERENCE}

1. Hedrick JL. A comparative analysis of molecular mechanisms for blocking polyspermy: identification of a lectin-ligand binding reaction in mammalian eggs. Social Reproduction Fertility Supplement 2007; 63: 409-19.

2. Densnoyers L, Therien I, Manjunath P. Characterization of major proteins of bovine seminal fluid by two-dimensional polyacrylamide gel electrophoresis. Molecular Reproduction and Development 1994; 37: 425-435.

3. Ashworth PJ, Miller NG, Plummer JM, Watson PF. Survival of ram spermatozoa at high dilution: protective effect of simple constituents of culture media as compared with seminal plasma. Reproduction. Fertility Development 1994; 6:173-180. 
4. Maxwell WM, Welch GR, Johnson LA. Viability and membrane integrity of spermatozoa after dilution and flow cytometric sorting in the presence or absence of seminal plasma. Reproduction Fertility Development 1996; 8: 1165-1178.

5. Pollard JW, Plante C, King WA, Hansen PJ, Betteridge KJ, Suarez SS. Fertilizing capacity of bovine sperm may be maintained by binding of oviductal epithelial cells. Biology of Reproduction 1991; 44:102-107.

6. Gwathmey TM, Ignotz GG, Mueller JL, Manjunath P, Suarez SS. Bovine seminal plasma proteins PDC-109, BSP-A3, and BSP-30-kDa share functional roles in storing sperm in the oviduct. Biology of Reproduction 2006; 75: 501507.

7. Suarez SS. Interactions of spermatozoa with the female reproductive tract: inspiration for assisted reproduction. Reproduction, Fertility and Development 2007;19:103-110.

8. Baas JW, Mohan PC, Shannon P. Factors in seminal plasma of bull that affect the viability and motility of spermatozoa. Journal of Reproduction. Fertility 1983; 68: 275-280.

9. Bernardini A, Hozbor F, Sanchez E, Fornes MW, Alberio RH, Cesari A. Conserved ram seminal plasma proteins bind to the sperm membrane and repair cryopreservation damage. Theriogenology 2011; 76: 436-447.

10. Graham JK. Effect of seminal plasma on the motility of epididymal and ejaculated spermatozoa of the ram and bull during the cryopreservation process. Theriogenology 1994; 41: 1151-1162.

11. Sankhal RS, Swamy MJ. The major proteins of bovine seminal plasma, PDC109, is a molecular chaperonin. Biochemistry 2010; 49(18): 3908-3988.

12. Gwathmey TM, Ignotz GG, Mueller JL, Manjunath P, Suarez SS. Bovine seminal plasma proteins PDC-109, BSP-A3, and BSP-30-kDa share functional roles in storing sperm in the oviduct. Biology of Reproduction 2006; 75: 501507.

13. Manjunath P, Lefebvre J, Jois PS, Fan J, Wright MW. New nomenclature for mammalian BSP gene. Biology of Reproduction 2009; 80: 394-397.

14. Manjunath P, Lefebvre J, Jois PS, Fan J, Wright MW. New nomenclature for mammalian BSP gene. Biology of Reproduction 2009; 80: 394-397.

15. Gwathmey TM, Ignotz GG, Mueller JL, Manjunath P, Suarez SS. Bovine seminal plasma proteins PDC-109, BSP-A3, and BSP-30-kDa share functional 
roles in storing sperm in the oviduct. Biology of Reproduction 2006; 75: 501507.

16. Pollard JW, Plante C, King WA, Hansen PJ, Betteridge KJ, Suarez SS. Fertilizing capacity of bovine sperm may be maintained by binding of oviductal epithelial cells. Biology of Reproduction 1991; 44: 102-107.

17. Suarez SS. Interactions of spermatozoa with the female reproductive tract: inspiration for assisted reproduction. Reproduction, Fertility and Development 2007; 19: 103-110.

18. Murray SC, Smith TT. Sperm interaction with Fallopian tube apical plasma membrane enhances sperm motility and delays capacitation. Fertility and Sterility 1997; 68: 352-357.

19. Therien I, Moreau R, Manjunath P. Bovine seminal plasma phospholipids binding proteins stimulate phospholipids efflux from epididymal sperm. Biology of Reproduction 1999; 6: 590-598.

20. McCauley TC, Zhang HM, Bellin ME, Ax RL. Purification and characterization of fertility-associated antigen (FAA) in bovine seminal fluid. Molecular Reproduction and Development 1999; 54: 145-153.

21. Manjunath P, Sairam MR. Purification and biochemical characterization of major acidic proteins (BSP-A1, BSP-A2 and BSP-A3) from bovine seminal plasma. Biochemical Journals 1987; 241: 685-692.

22. Hiron M, Harshan SS, Singh LP, Singh MK, Sudharani S, Ansari MR, Singh SK, Majumdar AC, Joshi P. Identification of PDC-109 like protein(s) in buffalo seminal plasma. Animal Reproduction 2009; 115: 306-311.

23. Pollard JW, Plante C, King WA, Hansen PJ, Betteridge KJ, Suarez SS. Fertilizing capacity of bovine sperm may be maintained by binding of oviductal epithelial cells. Biology of Reproduction 1991; 44:102-107.

24. Green, MR, Sambrook J. Molecular cloning: a laboratory manual. 4th ed. Cold Spring Harbor,NY 2012.

25. Singhal DK, Singhal R, Malik HN, Singh S, Kumar S, Kaushik JK, Mohanty AK, Malakar D. Molecular cloning and production of caprine recombinant Oct4 protein for generation induced pluripotent stem cells. Molecular Biology Reports 2015; 42:1583-1591.

26. Saugandhika S, Sharma V, Malik M, Mohapatra SK, Bondre VP, Kumar S, Mohanty AK, Malakar D. Molecular characterization of IFN-T expressed in 
buffalo embryonic trophoblasts and expression of recombinant BuIFN-T1a2 and BuIFN-T8 isoforms in E. coli. Elsevier 2016; 122:8e14.

27. Cardozo JA, Fernandezi JM, Farcado F, Abecia A, Muino-Blanco T, CebrianParez JA. Monthly variations in ovine seminal plasma proteins analyzed by twodimensional polyacrylamide gel electrophoresis. Theriogenology 2006; 66: 841850.

28. Oliphant G, Reynolds AB, Thomas TS. Sperm surface components involved in the control of the acrosome reaction. American Journal Anatomy 1985; 74:269283.

29. Langlais J, Roberts KD. A molecular membrane model of sperm capacitation and the acrosome reaction of mammalian spermatozoa. Gamete Research 1985; 12: $183-224$.

30. Jena MK, Malakar D, De AK, Garg S, Akshey YS, Dutta R, Sahu S, Mohanty AK, Kaushik JK. Handmade cloned and embryos - A comparison of different culture media and donor cells. Small Ruminant Research 2012; 105:255- 262 (2012).

31. Laskowski RA, MacArthur MW, Moss DS, Thornton JM. PROCHECK: a program to check the stereochemical quality of protein structures. Journal of Applied Crystallography 1993; 26: 283-291.

32. Wiederstein M, Sippl MJ. Protein sequence randomization: efficient estimation of protein stability using knowledge-based potentials. Journal of Molecular Biology 2005; 345: 1199-1212.

33. Kazmier K, Sharma S, Quick M, Islam SM, Roux B, Weinstein H, Javitch JA, Mchaourab HS. Conformational dynamics of ligand-dependent alternating access in LeuT. Nat Struct Mol Biol 2014; 21: 472-479.

34. Bingding H. MetaPocket: a meta approach to improve protein ligand binding site prediction. Omics 2009; 13(4): 325-330.

35. Xu Y, Tao Y, Cheung LS, Fan C, Chen LQ, Xu S, Perry K, Frommer WB, Feng L. Structures of bacterial homologues of SWEET transporters in two distinct conformations. Nature 2014; 515: 448-452.

36. Saugandhika S, Sharma V, Malik M, Saini S, Bag S, Kumar S, Singh, NK, Mohanty AK, Malakar D. Expression and Purification of Buffalo Interferon-Tau and Efficacy of Recombinant Buffalo Interferon-Tau for in Vitro Embryo Development. Cytokine 2015; 75(1): 186-196. 


\section{Supplementary S1}

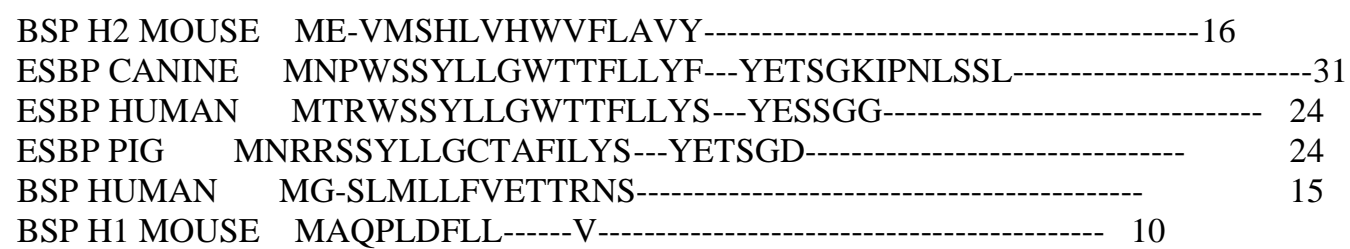

SPP HORSE $\quad$-----------------------------------------DLQTTGADH--------- 9

BSP 30

MAPLVGLFLIWAGASVFQQLHPVNGGDIPDPGSKPTPPGMADELPTETYDLPPEIYTTTF60

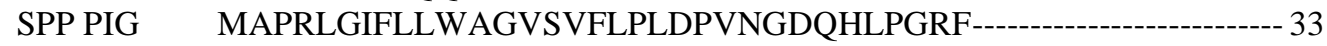

BSP A3 MALRLGLFLIWAGVSMFLQLDPVNGDEQLSEDNVILPKEKK------------------41

rBSP1 MALQLGLFLIWAGVSVFLQLDPVNGNQDEGVFTEL-TQDRP-----------------40

PDC109 MALQLGLFLIWAGVSVFLQLDPVNGDQDEGVSTEP-TQDGP-----------------40

BSP H2 MOUSE ----MYEL--------

NAELISHLHPPEQEISTDSCVFPFVYADGFHYSCISLHSDYDW 63

ESBP CANINE ----------GK----

HEFTKPWISIKEDQKDSCVFPFVYKGSSYFSCIKTNSFSPW74

ESBP HUMAN ------------------------MHEECVFPFTYKGSVYFTCTHIHSLSPW52

ESBP PIG ---------------------------TKDSCVFPFNYKGFTYFSCTRTNSLSPW 52

BSP HUMAN -SACIFPVI------

LNELSSTVETITHFPEVTDGECVFPFHYKNGTYYDCIKSKARHKW $\quad 68$

BSP H1 MOUSE -SICLFHSL-

FSFQVEDYYAPTIESLIRNPETEDGACVFPFLYRSEIFYDCVNFNLKHKW 68

SPP HORSE -SATVNPD

QQLIMTKHSATVTPENKCVFPFNYRGYRYYDCTRTDSFYRW 57

BSP 30

LPRTIYPQEEMPYDDKPFPSLLSKANDLNAVFEGPACAFPFTYKGKKYYMCTRKNSVLLW 120

SPP PIG ---------- LTPAITSDDKCVFPFIYKGNLYFDCTLHDSTYYW 67

BSP A3 --------------DPASGAETKDNKCVFPFIYGNKKYFDCTLHGSLFLW77

rBSP1 ----------------AELPEDSVPDEERVFPFTYRNRKHFDCTLRGSIFPW 76

PDC109

BSP H2 MOUSE

CSLDFQFQGRWRYCTAQDPPKCIFPFQFKQKLIKKCTKEGYILNRSWCSLTENYNQDGKW123 ESBP CANINE

CATRAVYNGQWKFCMADDYPRCIFPFIFRGKSHNSCITEGSFLRRLWCSVTSSFDENQQW 134 ESBP HUMAN

CATRAVYNGQWKYCQSEDYPRCIFPFIYRGKAYNSCISQGSFLGSLWCSVTSVFDEKQQW112 ESBP PIG

CATRAVYDGQWKYCLIEDYPRCVFPFIYRGRSHRNCIVEGSFFGKLWCSVTSSFDEKQQW 112 BSP HUMAN

CSLNKTYEGYWKFCSAEDFANCVFPFWYRRLIYWECTDDGEAFGKKWCSLTKNFNKDRIW 12 8

BSP H1 MOUSE

CSLNKTYQGYWKYCALSDYAPCAFPFWYRHMIYWDCTEDGEVFGKKWCSLTPNYNKDQVW SPP HORSE

CSLTGTYSGSWKYCAATDYAKCAFPFVYRGQTYDRCTTDGSLFRISWCSVTPNYDHHGAW 11 7

BSP 30

CSLDTEYQGNWKFCTERDEPECVFPFIYRKKSYESCTRVHSFFWRRWCSLTSNYDRDKAW 180 SPP PIG

CSVTTYYMKRWRYCRSTDYARCALPFIFRGKEYDSCIKEGSVFSKYWCPVTPNYDQDRAW 12 7

BSP A3

CSLDADYTGRWKYCTKNDYAKCVFPFIYEGKSYDTCIIIGSTFMNYWCSLSSNYDEDGVW137

rBSP1 CSLDANYVGRWKYCAQRDYAKCVFPFIYGGKKYETCTKTGSMWM-

SWCSLSPNYDKDRAW 135 


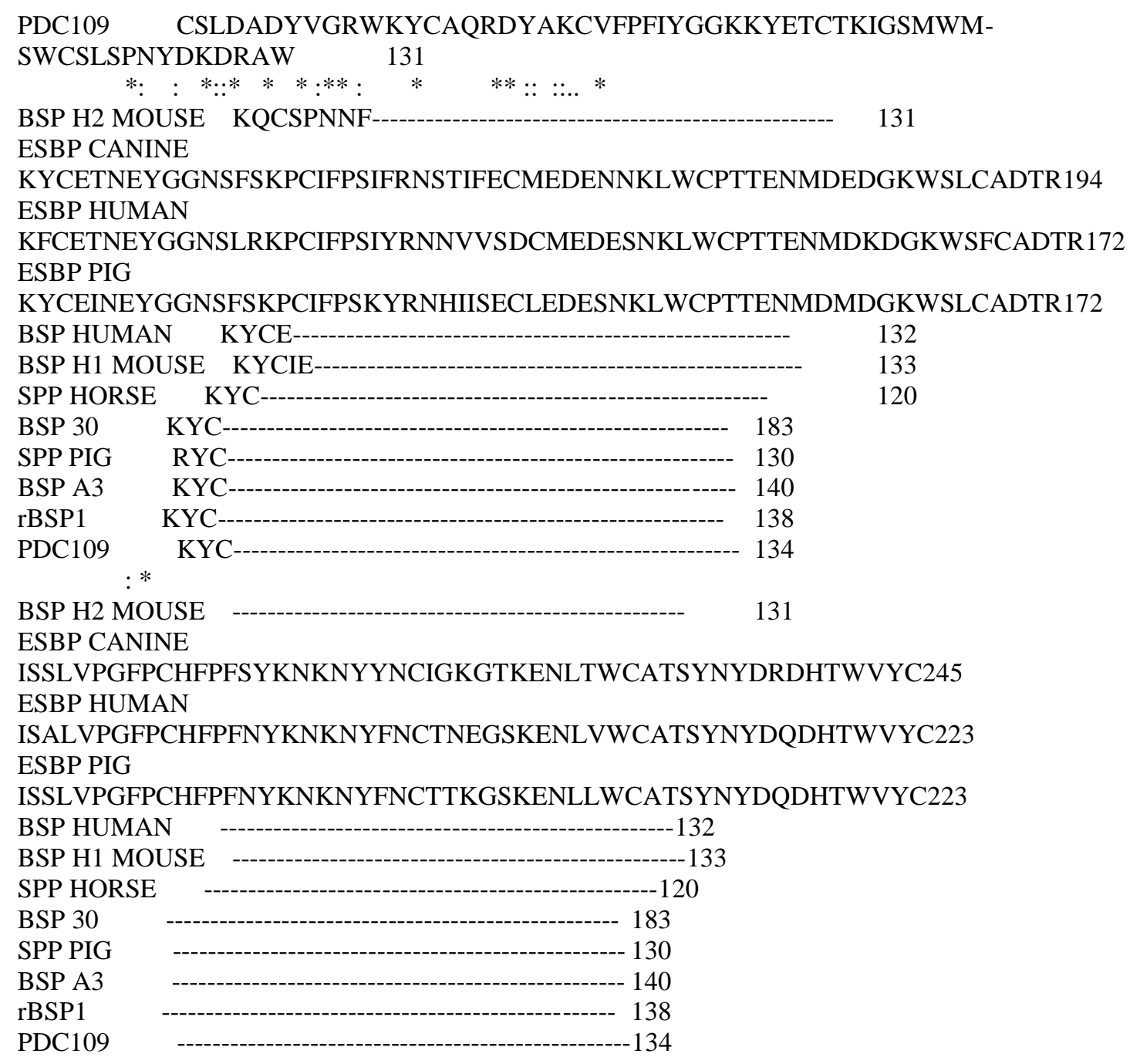

Supplementary S2 Multiple Alignments of Amino Acids Sequence of seminal vesicular protein of different species retrieved from GenBank. Residues Identical to the Sequences of Indicated by Dots (.). Spaces or Dash (-) Denotes Gap \& star (*) Denotes conserved amino acid residues.

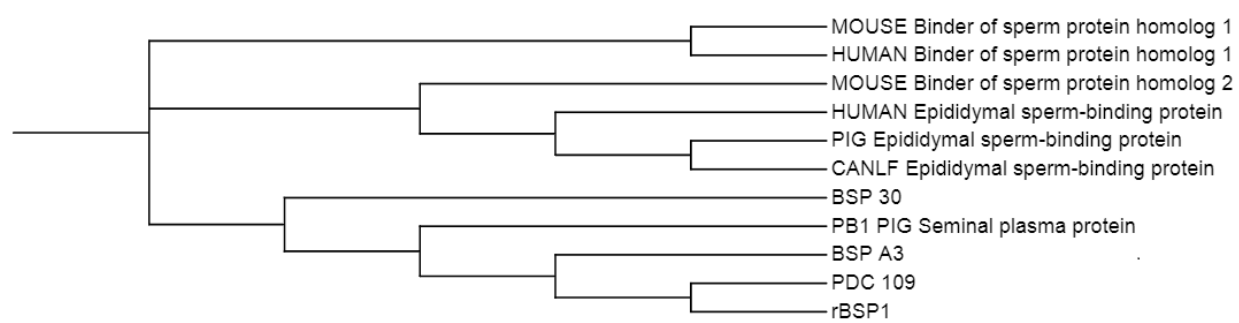

Supplementary S2 Schematic Maximum Likelihood Consensus Tree with 1000 Boot straps. The Bootstrap Confidence value at the Nodes Represent the percentage of Times the Group occurred out of 1000 Trees \& the Bar represents the Genetic Distance. 
Supplementary S3 Binding energy, Ligand efficiency and Hydrogen bond formation of rBSP1 protein.

\begin{tabular}{|c|c|c|c|c|c|}
\hline SN & Compounds & Binding Energy & Ligand & \multicolumn{2}{|c|}{ Hydrogen bond } \\
\cline { 5 - 6 } & & $(\mathbf{k c a l} / \mathbf{m o l})$ & Efficien & Residues & Bonds \\
& & & cy & & \\
\hline 1 & Heparin & -5.44 & -0.25 & ASN 26 & 4 \\
& & & & THR 33 & \\
& & & & ARG 53 & \\
& & & & ASP 66 & \\
\hline 2 & Phosphatidyl & -5.21 & -0.07 & THR 33 & 2 \\
& Choline & & & GLU 34 & \\
\hline
\end{tabular}

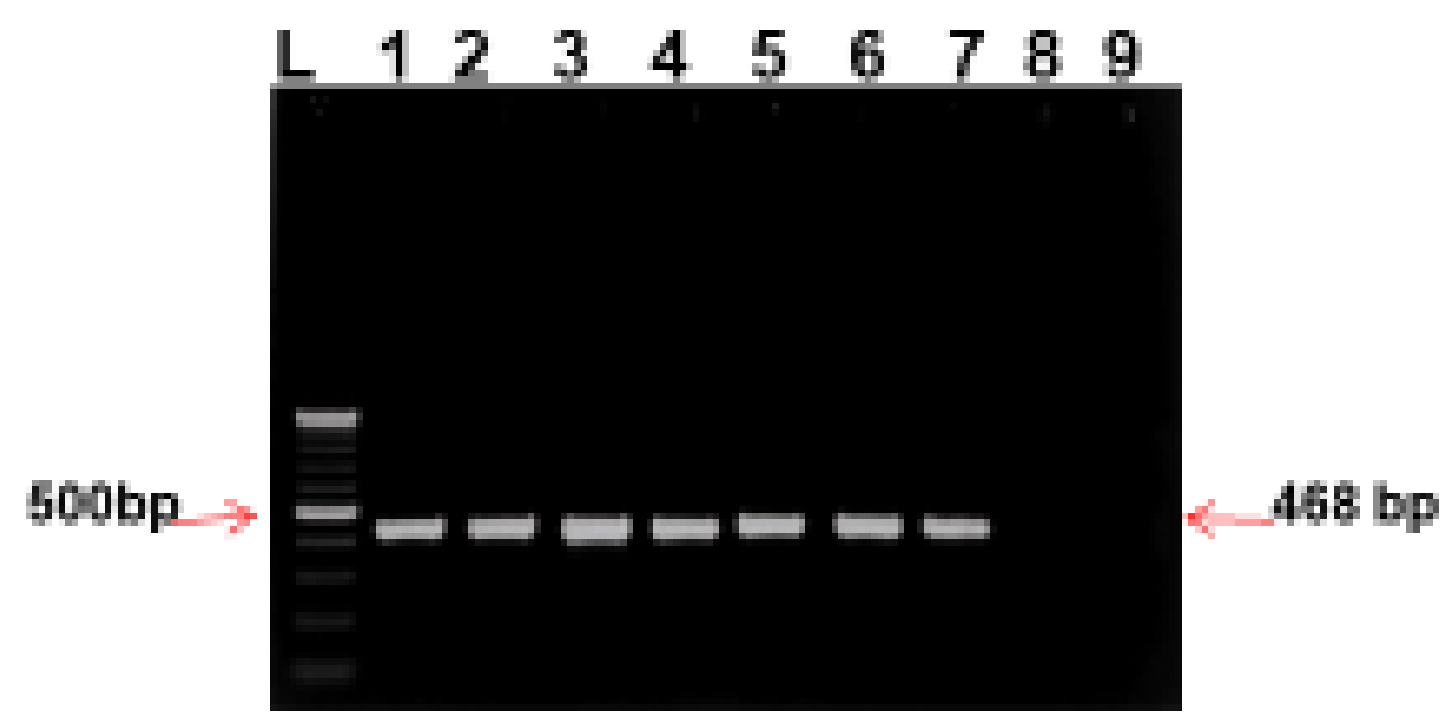

Supplementary S4 Colony PCR of BSP gene where Lane M: DNA Ladder; Lane 1-

7: Positive clones. 